\title{
TRUST \\ and the Ethics of Health Care Institutions
}

by SUSAN DORR GOOLD

Though trust is essential to relationships between people, including that between patient and clinician, its role in organizational ethics is largely unexplored. Nonetheless, trust is also ideally a part of the relationship between patient and health care institution, both because it is desirable in and of itself, and because it makes for better medical care.

$\mathrm{t}$ is widely acknowledged that trust is a vital component of and basis for relationships between clinicians and patients. These interpersonal trust relationships have moral content-fidelity to trust is morally praiseworthy, betrayal of trust morally blameworthy. ${ }^{1}$ The need for trust and reliance on trust are especially important in health care because of patients' acute vulnerability to suffering, lost opportunity, and lack of power. Patients' vulnerability to organizations is arguably even greater than to physicians, yet while physicians acknowledge consequent ethical obligations, most institutional obligations are couched in contractual terms. This contract

Susan Dorr Goold, "Trust and the Ethics of Health Care Institutions," Hastings Center Report 31, no. 6 (2001): 26-33. model assumes a level playing field for its parties, even though most would agree that "consumer sovereignty" is far from the norm in the health care marketplace.

My aim in this paper is to describe the relationship between individuals and health care institutions, using trust as a conceptual framework, then to draw conclusions for the ethics of health care organizations. In the last section, I will discuss what conditions or circumstances could influence trust in health care institutions, and contrast them with conditions that influence trustworthiness. It is my belief that a sociological understanding of institutional trust provides insight into the relationships between individuals and health care institutions and hence the morality of organizational actions. 
Can an Organization Be Ethical?

ince organizations do not clearly Shave the same sort of "moral agency" attributed to people, philosophers have debated whether they have any intrinsic moral obligations. Most philosophers and organizational theorists agree, however, that organizations have an identity distinct from the sum of the individuals within them, and thus can be treated as moral actors. ${ }^{2}$

There is no question that organizations are dominant actors in modern society. Organizations expand our abilities in ways that allow common people to do uncommon things: a trauma center is able to achieve what no individual, no matter how skilled or talented, could hope to accomplish. As dominant actors in health care, organizations merit our moral attention for several reasons. First, they create role expectations that have moral content. For example, nurses and physicians in a trauma center are expected to be patient advocates, and the center's administrator is expected to engineer the system so as to maximize efficiency. Organizations shape behavior through these role expectations, and through their policies, practices, and culture. Nurses have traditionally been granted less authority than physicians, for instance, but their authority varies across different types of organizations.

In addition to creating role expectations, organizations as actors respond to social conditions. ${ }^{3}$ Hospitals, physician groups, and insurers, for instance, respond to the medical marketplace with utilization review, prices, and changes in benefits. Finally, organizations have a normative structure. They set goals and express values and norms in addition to creating role expectations. ${ }^{4}$ In health care, changes in organizations, changes in delivery and financing arrangements, changes in the context of care, change the experiences of health care for individual patients, in- cluding which and how much care they receive, when they receive it, and how it is received. Organizational decisions also affect potential future patients, employees, other organizations, and the community. Given the dominant place of organizations in modern society, and in particular the change occurring in health care organizations, it behooves scholars to examine the ethics of health care organizations. What framework, what theory of right behavior, can be used to examine organizational ethics in health care?

\section{Interpersonal Trust in Health Care}

heories and principles of
bioethics rely to varying degrees
on intrinsic or instrumental justifica-
tions for imposing moral duties on
clinicians. An intrinsic justification is
one that asserts the value of ethics as
an end in itself because of the basic
and fundamental importance of
maintaining morality. An instrumen-

\section{Given the dominant place of organizations in modern} society, and in particular the change occurring in health care organizations, it behooves scholars to
examine the ethics of health care organizations.

tal justification is one that sees moral injunctions as serving a useful purpose, usually one that promotes a more objective aspect of social welfare. Classic moral injunctions against lying, stealing, or killing, for instance, can be justified in either manner.

There are certain intrinsic and universal aspects of the clinicianpatient relationship that warrant a strong ethical code. Patients typically encounter clinicians in a state of great stress and vulnerability in which they depend on the clinician's greatly superior skill and knowledge. In these circumstances, trust is an essential and prevalent attribute of the rela- tionship. ${ }^{5}$ Trusting relationships can be valued in and of themselves, and have an inherently moral component. ${ }^{6}$ Thus clinical ethics rightly focuses on establishing the elements of trustworthiness that are essential to deserving trust.

Trust is not simply an end in itself; it is also necessary to achieve the ends of medicine. Trust is essential in order for patients to submit to examination and treatment, to reveal sensitive information, to follow treatment recommendations, and to adhere to treatment regimens. For both intrinsic and instrumental reasons, then, a primary objective of medical ethics is to maintain the conditions necessary to preserve trust, avoid abuses of trust, and promote trustworthiness by clinicians.

\section{Frameworks for Institutional Ethics}

If institutional ethics were simply a derivative of clinical ethics, it could be constructed by means of instru- mental justifications, simply by asserting that the role of health care institutional ethics is to support the functioning of clinicians. Institutional ethics would then prescribe whatever is necessary to promote and sustain the moral aspects of health care professionals' work, such as helping to guard the confidentiality of medical records. This perspective is evident in much of the literature addressing the ethics for health care administrators. ${ }^{7}$ This literature also addresses conflicts between the selfinterest of a manager and the goals or mission of the institution, and the interaction between clinical ethics and conventional business ethics (which 
is concerned with such issues as fair competition and honesty in advertising). The resulting moral framework is aimed primarily at individual administrators within institutions, and so does not fully consider the organization itself as a moral actor in society.

Merely transplanting the ethics of commercial transactions into the health care arena is plainly not enough, ${ }^{8}$ in spite of the fact that health care business ethics often recognizes a distinct institutional perspective. ${ }^{9}$ An ethics for health care organizations needs a framework that is different from either individual clinicians, individual administrators, or collective commercial enterprises. Health care, or at least health, is a primary good. It is necessary to achieve one's life goals and contributes to equality of opportunity. ${ }^{10}$ In addition, the sick are emotionally and physically vulnerable. Imbalances of knowledge and power, which contribute to this vulnerability, are present in health care relationships to a greater extent than they are in other arenas. ${ }^{11}$ Health care occupies a central role during times when individuals confront physical weakness, suffering, death, and birth. These are life events with profound, even spiritual meaning. Most relevant for health care organizations, the provision of health care invariably relies on pooled resources. The burdens and benefits of health care are distributed among a population of individuals so that both one's health and the resources to meet health care needs are entrusted to health care organizations.

The basis for an adequate moral theory of health care organizations is thus more appropriately grounded in their relations. Such an approach is a limited form of role morality - that is, of an approach to morality that addresses the roles that actors have assumed or been assigned. In the case of institutions, roles are typically defined either by contract or by social expectations, including but not limited to those imposed by regulation.
Health care institutions, as businesses in a market-based system, have tended to characterize their relationships as contractual obligations rather than on what the law regards as "fiduciary responsibility." 12 For instance, an insurer, rather than seeing itself as a trustee of pooled resources for which it has a moral obligation to make good decisions about what is covered under a broad, discretionary standard, tends to specify in its contract as precisely as possible what is and is not covered and under what circumstances. Even so, language such as "medically necessary" or "experimental" requires interpretation in its application to coverage decisions. ${ }^{13}$ This contractual model of individual-institutional relationships emphasizes honesty (or promise keeping), fair competition, and other conventional business mores.

The contractual model is grossly inadequate for health care institutions, however, because the relationships are not between equals. In the selection of health insurance, for instance, it would be a stretch to characterize consumers as informed and imaginative, having multiple options and free exit. ${ }^{14}$ Medical decisions in particular are made under conditions of uncertainty and risk that place the "consumer" in an especially vulnerable position. In addition, unlike typical business-consumer relationships, the purchaser of health care is not the consumer. Rather, employers and government purchase health insurance (which then purchases health care) and therefore determine what products are available. Health care organizations are accountable not just to patients but also to purchasers, stockholders (or other sources of capital such as banks or contributors), future and potential patients, and the community. These conflicts in accountability further dilute the protections that might normally exist in a typical bilateral contract between business and customer.

\section{Control or Trust?}

nforcing ethical behavior is one - way to manage this complexity and guard against abuse. Enforcement could take a variety of forms. For example, extensive monitoring or regulation, and to a lesser extent contracts, can substitute for trust, and to a considerable extent, in fact, society has chosen monitoring over trust for health care organizations. Government regulation and legal liability impose numerous types of oversight on hospitals, insurers, and health maintenance organizations, for instance, and many more, such as the Managed Care Bill of Rights for Consumers Act of 2001, are currently being debated (H.R. 2497). In these regimes, institutional morality then tends to consist of complying with the rules set by contract or imposed by government. Both contractual specification of duties and external monitoring through regulation, however, are costly and imperfect means of protecting patients.

Another way to reduce the potential for abuse through enforcement is to reduce the scope of the institution's relationship with patients or the degree of patients' vulnerability. Health plans' discretion over coverage decisions could be limited, for instance, or the financial incentives they use to affect treatment decisions could be moderated. These limits also have costs, however, since they may restrict organizational innovation and the ability to improve efficiency or quality.

Enforcement is not the only method for managing the complex relationship between health care organizations and the people affected by them, however. Self-regulation provides a less costly and potentially more beneficial form of protection. Either individually or collectively, that is, health care institutions could guard against their own potential to abuse their relationships with patients by means of self-imposed and self-policed norms of behavior. 
Self-regulation invokes trust. ${ }^{15}$ Institutions in effect say "trust us because ...," where the reasons for trust are specified in institutionalized elements of trustworthiness, such as loyalty, caring, honesty, competence, confidentiality, and fairness. A moral institution is one that adheres to the standards of trustworthiness that it establishes for itself or that are necessary to justify the level of trust it claims for itself. These ethical standards are not externally imposed, and they are not necessarily inherent or universal (although some certainly are, such as honesty and competence). Trust in this construct is an alternative to the states of distrust or suspicion that give rise to more regulatory regimes. Trust is also an alternative or supplement to arms-length contractual relations that are characterized not so much by distrust as by a diminished level of trust, in which each party looks after its own interests and the standards of conduct take on a more specified and legal character. Because trust is an alternative to these regimes, it is less mandatory for institutions than for physicians. Once institutions invoke trust, they give rise to a set of ethical obligations or objectives to establish trustworthiness and earn trust. ${ }^{16}$ In short, institutions that invoke trust assume a role-based ethic that is grounded in trustworthiness.

It is not necessary, or even desirable, to disassemble or avoid regulation, monitoring, or contracts completely to invoke a trust-based ethics for organizations. On the contrary, regulation and monitoring mechanisms can strengthen trust, since they deter untrustworthy behavior, and enhance the trusting party's expectations. However, higher levels of trust can help avoid the high costs of greater monitoring. ${ }^{17}$

Proposing a role morality based in trust is only the beginning of the inquiry, however. Where it may lead depends entirely on the circumstances and structures of different institutions. The results cannot be patterned automatically after interpersonal trust between clinicians and patients, since organizations are by nature more complex and multidimensional. Instead, a role-based or function-based morality that focuses on relationships acknowledges the differences between types of organizations and even between different roles within one organization. Patients seeking care are not the only individuals with relationships to health care institutions. Potential patients, a group practice's panel, or insurer's enrollees, for instance, are other interested parties whose relationship with the organization needs to be clarified and examined. A hospital or nursing home is primarily a provider of health care services, and an indemnity insurer primarily a payer for health care, but

\section{What is Trust?}

nstitutional trust is the subject of a growing literature grounded in organizational theory, psychology, and sociology. We can also learn a great deal about institutional trust from the literature on interpersonal trust, in spite of important differences between the two sorts. In health care, of course, institutional trust would differ from that which patients have in physicians because of the different roles of physicians and institutions. ${ }^{19}$ Physicians are providers, for example, but the provider role is not the only role assumed by health care organizations. Organizations also pay for health care, provide facilities and equipment, and supervise employees.

\section{It is not necessary, or even desirable, to disassemble or avoid regulation, monitoring, or contracts completely to invoke a trust-based ethics for organizations.}

a managed care organization or a capitated group practice is both provider and payer. A single organization may even be a patient's provider, insurer, and employer. All organizations are employers and members of communities.

Just as our expectations for what an adult should do for a child vary according to whether the adult is parent, teacher, doctor, neighbor, or a stranger, our expectations of an organization may depend on whether it is, for the purposes of judging the morality of actions, employer, provider, payer, or some combination. Bioethics has traditionally tended to the individualistic and the present, addressing what should be done in this case at this time. For those organizations that must balance the needs and claims of individuals and collectives, including future patients, a sole focus on the present individual is inappropriate. ${ }^{18}$
According to Diego Gambetta, interpersonal trust is "the specific expectation that another's actions will be beneficial rather than detrimental." ${ }^{20}$ A trust-based relationship is composed of a number of elements. ${ }^{21}$ A trust-based relationship presupposes the vulnerability, reliance, and dependence of the truster. As Annette Baier has written succinctly, "Risk is of the very essence of trust." 22 In health care, this vulnerability arises from the experience of illness, from the imbalance between physicians' and patients' knowledge, from patients' lack of power within health care institutions, and from the very importance of health and well-being.

Health, well-being, and private information are the "trust objects" what one is being trusted with-in most interpersonal health care relationships. For health care organizations, the objects of trust might also include financial well-being in the event of catastrophic illness, livelihood as an employee, or the health of neighbors and community in addi- 
tion to one's own. Trust relationships are also found in conditions where there is risk and uncertainty in decisionmaking - conditions that are certainly present in health care.

Trusting parties expect-as specified in Gambetta's definition - beneficence; that is, they expect that the trustee will be concerned for their well-being and interests. Along with expectations of beneficence are expectations of advocacy-expectations that the trustee will act on one's behalf in negotiations or dealings with third parties - and expectations of competence or of good outcomes. The truster gives the trustee discretionary power over decisions in conditions of risk and uncertainty, and expects the trustee to use this power on the truster's behalf. We are quite conditioned to thinking about trust for interpersonal relationships, as between parent and child, teacher and student, or doctor and patient, but on close examination, trust (or distrust) in institutions is widespread. There is talk of the American people losing trust in government. Trust is needed between suppliers and purchasers of goods in order to allow the market to function and within organizations to allow them to function smoothly and efficiently. Trust is the grease that keeps the wheels of society moving at both individual and organizational levels. ${ }^{23}$

How are institutional and interpersonal trust alike in the context of health care? First, patients (or potential patients) are vulnerable to both individuals and institutions (research firms, hospitals). Imbalances of power, particularly of knowledge and expertise, are unavoidable in both types of relationships. Conditions of risk, and what is at stake for vulnerable patients, are equally important. Uncertainty of outcomes is, likewise, a feature of interactions with both individuals and health care institutions.

How does institutional trust differ from interpersonal trust, besides having multiple (and perhaps conflicting) trust objects? First, expectations of competence might be stronger. In- dividuals' errors can be sympathetically overlooked, whereas institutional, and especially institutionalized error, is more frightening and less forgivable. ${ }^{24}$ Second, expectations of beneficence, and particularly of advocacy, are weaker, because they must be balanced by institutional fairness. The importance attached to distributive and procedural justice and their relationship, which is absent from most considerations of an individual's trustworthiness, could be explained by a trust-based theory of organizations. ${ }^{25}$ That is, if an organization must distribute benefits and burdens (health care costs or job layoffs, for example), then individuals' moral judgments about that distribution depend on both the outcome (how much she gets or pays) and the process the institution followed to determine the distribution.

\section{What Influences or Justifies Trust?}

W e now turn to what justifies trust, and what conditions predispose to stronger or weaker trust relationships. There is an important distinction between influencing (affecting) trust and justifying (observing or deserving) trust. Some behaviors, such as respectful treatment, both strengthen and justify trust. Some, like public relations campaigns, affect perceptions and thus increase trust, but do not justify it. Others, like employing proper sterilization techniques, justify but do not strengthen trust; they are unperceived by trusters but make the truster more trustworthy. Finally, actions like deception both undermine trust and justify distrust.

A necessary criterion and the first step toward a justified trust-based relationship is acceptance. ${ }^{26}$ The trustee organization must accept from the truster the decisionmaking power and expectations that come with it. This is a minimum condition. An individual who arrives at a bank, puts a big bag of money on the floor, and leaves, does not have a trust-based relation- ship for the safe, productive care of that money, no matter how much he says he trusts the bank to take care of it. Rather, organizations must accept, usually in an explicit way, their discretionary power over a particular trust object. With this acceptance, and only after it, come the moral obligations that follow from a trust relationship. Hospitals accept a certain power over private information, for example, and given this acceptance there is a legitimate social expectation that patient information will be kept confidential by hospital staff, even if the patient never asked for or demanded such confidentiality.

It is important to note that interpersonal and institutional trust are intimately related. Trust in an institution can influence the degree of trust in individuals who are part of that organization. Conversely, experiences with individuals can influence trust in institutions. For example, trust in the profession of medicine influences the trust that individuals have for doctors, even during their first visit. Betrayal of trust by a particular physician, however, can adversely affect one's trust of all other physicians, the profession of medicine, and the organizations in which that physician practices. Betrayals of confidences by employees also make the institution less trustworthy. ${ }^{27}$ Similarly, unauthorized release of information by health care organizations may make patients less likely to entrust private information to individuals affiliated with those organizations.

One of the most important conditions affecting trust is knowledge. In order to have expectations of beneficence, advocacy, and competence, knowledge of the trustee's behavior is needed. In particular, it is important for that behavior to be predictable or reliable. Even if an institution's behavior is predictably unfavorable in some ways - it never has adequate parking, for example-knowing what to expect is an important condition affecting the ability to trust wisely. Of course, knowledge of or experience with actions of beneficence, advocacy, 
competence, and fairness justify and strengthen trust, whereas bad experiences undermine trust. The powerful influence of knowledge explains why the history of a trust-based relationship is important. The longer one has known an organization or individual, the more experiences one has had without surprise or betrayal, the more the organization is known, the more trust is likely to exist in that relationship. Reputation, or secondhand experiences related by friends or acquaintances, also reinforce trust (or distrust).

The important role of knowledge also explains the need for openness and honesty. Betrayal undermines trust out of proportion to its frequency or effect on outcomes in interpersonal and institutional relationships. ${ }^{28}$ In all likelihood, this is a manifestation of "tip of the iceberg" thinking. In conditions of risk, uncertainty, and the granting of discretionary power to another, where extensive monitoring is impossible or unacceptably costly, an experience of betrayal generates a concern that there may be other, unknown actions that are harmful or dishonest. Betrayal is also powerful because it causes individuals to doubt their own capacity for wise trusting and hence influences all of one's trustbased relationships. Paradoxically, there is a propensity for individuals to disbelieve in violations of trust. Sometimes the need to trust is so strong or the options so few that individuals can permit a type of cognitive dissonance when evaluating another individual or organization's behavior. This may be less true for individual-institutional trust than for interpersonal trust, however, because relationships with organizations are often impersonal. Hence openness and honesty may be even more important for organizations than for interpersonal trust relationships.

An important social condition affecting trust is deterrence. The more deterrents there are to betrayal, dishonesty, or incompetence, and the more these deterrents are known by trusters, the higher the expectation

that trust will be honored. Usually deterrents are formal and explicit-in statutes, liability, and elections, for example-but implicit deterrents such as the threat of bad publicity also affect the expectations of individuals for beneficence, advocacy, and good outcomes. Legislative action regarding "gag clauses," third party appeals processes, and the timeliness of organizational responses to complaints deter practices that undermine trust and thus could strengthen (and help justify) trust in managed care organizations.

Yet another condition influencing trust is a sense of shared values. Sometimes called "identification-based trust," ${ }^{29}$ the perception that a trustee

The important role of knowledge also explains the need for openness and honesty. Betrayal undermines trust out of proportion to its frequency or effect on outcomes.

has internalized the truster's preferences because of shared values can produce a very powerful trust in an individual or institution. This may exist, for instance, in a church, or for employees within the same firm..$^{30}$ Of course, the perception of shared values requires knowledge of those values, thus openness and honesty are again necessary preconditions. A sense of shared values is also affected by perceived difference or sameness. Women may distrust an organization dominated by men, and minorities may distrust an institution run by whites. Thus while homogeneity within an institution may strengthen the trust of like individuals, it will weaken the trust of those from dissimilar groups.

A sense of shared values is also profoundly affected by experiences that reflect congruence in goals or a lack thereof. An initial distrust produced by dissimilarity, for instance, can eventually be overcome if the individual sees the institution consistently demonstrate its fidelity to trust and act in ways that show it shares the individual's values and goals. Shared values are also strongly influenced by voice-by the perception that one has a role in organizational decisionmaking. ${ }^{31}$ Organizational justice, whether procedural or distributive, is thus an important component of institutional trust relationships. This element of institutional trust has no easy parallel with interpersonal trust-based relationships, even in the health care arena. A fair distribution of benefits and burdens, or a fair process of decisionmaking, is more important for organizations than for individuals because of organizational control over pooled resources. In particular, if an individual perceives that a distribution of benefits and burdens has not been in her favor, her perception of the fairness of the process or procedure for distributing those benefits and burdens becomes increasingly important to her overall evaluation of the organization. ${ }^{32}$ The reason that individuals may accept, and perceive as fair, an unfavorable distributive outcome may be explained by the effect that their experience of the process of decisionmaking has on their expectations about how they might be treated in the future. In other words, a bad outcome this time can be outweighed by the expectation that, because the decisionmaking process is fair, they are likely to be treated fairly over the long term. It has not been shown that this relationship exists in the distribution of health care benefits and burdens, but there is no reason to suspect that it would be different. Lack of knowledge about the process of organizational decisionmaking, or a percep- 
tion that those decisions are arbitrary, can both make the decisions still more unacceptable and worsen others' opinions of them.

\section{Organizational Roles}

Ising the conceptual model of trust, what are the roles of health care organizations and their corresponding trust objects? One role for health care organizations is as a provider of care; as such they are entrusted with the health, well-being, treatment decisions, and private information of individual patients (and potential patients). A commitment to competence, beneficence, confidentiality, and other values follows once the organization has accepted this role. Most health care organizations also pay for health care and thus are entrusted with pooled, limited resources as well as the financial wellbeing of individuals confronting illness, especially catastrophic illness. Prudent use of resources, fidelity to and beneficence for the very ill subscriber are moral obligations that follow from the "insurer" role and, indeed, the role of any health care organization that makes budgetary decisions affecting patient care. Health care organizations may be places where clinicians work, and thus patients may also trust the organization to safeguard and protect the relationships, themselves trust-based, between clinicians and patients. Health care organizations are also, of course, employers, and thus are trusted with employees' livelihood and financial security. Finally, health care organizations are often the result of social investment, whether private, public, or philanthropic, and they are therefore trusted with the control and prudent use of community resources, and frequently with overseeing the health of the community.

How does this analysis of trust, ethics, and health care organizations help address the many thorny moral questions facing those organizations today? From a practical perspective, trust and trustworthiness are familiar concepts to individuals trained in business or administration, although they may more often think of trust in their employees or of customer trust in the organization. The recognition that organizational morality depends on the role of the organization in a specific situation could illuminate some of the hard cases by, for instance, revealing conflicting roles within a single organization's relationship to an individual. Specific roles accepted by an organization allow ethical priority-setting (competence for providers, fairness for payers). Since trust in an organization depends on the actions of individuals in it, and trust in individuals depends on trust in their organization, using trust allows micro-, meso-, and macro-levels of analysis to interact. Finally, for organizations desiring or aspiring to the highest levels of identification-based trust, based on shared values, they will need to go beyond minimum standards of openness and honesty and incorporate the voices of those whose trust they seek.

\section{References}

1. E.D. Pellegrino and D.C. Thomasma, The Virtues in Medical Practice (New York and Oxford: Oxford University Press, 1993).

2. P.H. Werhane, "The Ethics of Health Care as a Business," Business and Professional Ethics Journal 9 (Fall-Winter 1990): 7-20.

3. P.A. French, "The Corporation as a Moral Person," American Philosophical Quarterly 3 (1979): 207-15.

4. W.R. Scott, Organizations: Rational, Natural, and Open Systems, 3rd. Ed. (Englewood Cliffs, N.J.: Prentice-Hall, Inc., 1992).

5. M.A. Hall and R.A. Berenson, "Ethical Practice in Managed Care: A Dose of Realism," Annals of Internal Medicine 128, no. 5 (1998): 395-402; D. Axelrod and S.D. Goold, "Maintaining Trust in the Surgeon-Patient Relationship: Challenges for the New Millennium," Archives of Surgery 135, no.1 (Jan. 2000): 55-61; D. Mechanic, "The Functions and Limitations of Trust in the Provision of Medical Care," Journal of Health Politics, Policy, and Law 23, no. 4 (1998): 661-86.

6. See ref. 1, Pellegrino and Thomasma, The Virtues in Medical Practice; see ref. 5, Axelrod and Goold, "Maintaining Trust," pp. 55-61; R. Rhodes and J.J. Strain, "Trust and Transforming Medical Institutions," Cambridge Quarterly of Health care Ethics 9, no. 2 (Spring 2000): 205-17.

7. K. Darr, Ethics in Health Services Management, 3rd Ed. (Baltimore: Health Professions Press, Inc., 1998); J.A. Worthley, The Ethics of the Ordinary in Health care: Concepts and Cases, (Chicago: Health Administration Press, 1997); P.B. Hofmann, "Assessing Medical Efficacy: A Neglected Administrative Necessity," Hospital Progress 60, no. 10 (Oct. 1979):45-7; J.R. Griffith, The Moral Challenges of Health Care Management (Chicago: Health Administration Press, 1996).

8. W.K. Mariner, "Business vs. Medical Ethics: Conflicting Standards for Managed Care," Journal of Law, Medicine \& Ethics 23, no. 3 (1995): 236-46; J.F. Peppin, "Business Ethics and Health Care: The Re-emerging Institution-Patient Relationship," Journal of Medicine and Philosophy 24, no. 5 (October 1999): 535-50.

9. L.J. Weber, "Ethical Downsizing. Managers Must Focus on Justice and Human Dignity," Health Progress 75, no. 6 (July-August 1994): 24-26.

10. N. Daniels, Just Health Care: Studies in Philosophy and Health Policy (Cambridge, New York: Cambridge University Press, 1985).

11. H. Brody, The Healer's Power (New Haven and London: Yale University Press, 1992); M.A. Hall, Chapter 2: "Relevant to the Importance of Interpersonal Trust in Doctor-Patient Relations, on Account of Intense Vulnerability and Immense Power," in Making Medical Spending Decisions: The Law, Ethics and Economics of Rationing Mechanisms (Oxford: Oxford University Press, 1997).

12. L.B. McCullough, "A Basic Concept in the Clinical Ethics of Managed Care: Physicians and Institutions as Economically Disciplined Moral Co-Fiduciaries of Populations of Patients," Journal of Medicine and Philosophy 24 (1999): 77-97.

13. G. Anderson, M.A. Hall, and T.R. Smith, "When Courts Review Medical Appropriateness," Medical Care 36, no. 8 (Aug. 1998): 1295-302; N. Daniels and J.E. Sabin, "Last Chance Therapies and Managed Care: Pluralism, Fair Procedures, and Legitimacy," Hastings Center Report 28, no. 2 (1998): 27-41.

14. See ref. 11, Hall, "Relevant to the Importance of Interpersonal Trust;" G.J. Annas, "Patients' Rights in Managed Care-Exit, Voice, and Choice," New England Journal of Medicine 337 (Jul 17, 1997): 210-15; M.A. Rodwin, Medicine, Money, and Morals: Physicians' Conflicts of Interest (New York: Oxford University Press, 1993). 
15. F. Fukuyama, Trust: Social Virtues and the Creation of Prosperity (New York: Free Press, 1995), p 457; N. Luhmann, Trust and Power (New York: Wiley, 1979).

16. L.T. Hosmer, "Trust: 'The Connecting Link Between Organizational Theory and Philosophical Ethics," The Academy of Management Review 20 (April 1995): 379403.

17. See ref. 15, Fukuyama, Trust: Social Virtues.

18. M.D. Smith, "The Virtuous Organization," Journal of Medicine and Philosophy 7, no.1 (Feb. 1982): 35-42; D.C. Blake, "Organizational Ethics: Creating Structural and Cultural Change in Health Care Organizations," Journal of Clinical Ethics 10, no. 3 (Fall 1999): 187-93.

19. B.H. Gray, "Trust and Trustworthy Care in the Managed Care Era," Health Affairs 16, no. 1 (1997): 34-49; D. Mechanic and M. Rosenthal, "Responses of HMO Medical Directors to Trust Building in Managed Care," Milbank Quarterly 77, no. 3 (1999): 283-303, at 273.

20. D. Gambetta, ed., Trust: Making and Breaking Cooperative Relations (New York: Blackwell, 1998).
21. R. Jackson, A Philosophical Exploration of Trust, (Ph.D. dissertation, Michigan State University) (1995); A. Baier, "Trust and Antitrust," Ethics 96 (Jan 1986): 231-60.

22. A. Baier, Moral Prejudices: Essays on Ethics (Cambridge, Massachusetts, \& London: Harvard University Press, 1996), p. 196.

23. See ref. 15, Fukuyama, Trust: Social Virtues.

24. L.K. Altman, "Getting to the Core of Mistakes in Medicine," New York Times (29 February 2000).

25. J. Brockner and P. Siegel, "Understanding the Interaction Between Procedural and Distributive Justice: The Role of Trust," in Trust In Organizations: Frontiers of Theory and Research, ed. R.M. Kramer and T.R. Tyler (Thousands Oaks, CA: Sage Publications, 1996).

26. See ref. 21, Jackson, A Philosophical Exploration of Trust; see ref. 22, Baier, Moral Prejudices.

27. P.A. Ubel, M.M. Zell, D.J. Miller, G.S. Fischer, D. Peters-Stefani, and R.M. Arnold, "Elevator Talk: Observational Study of Inappropriate Comments in a
Public Space," American Journal of Medicine 99, no. 2 (August 1995): 190-94.

28. See ref. 22, Baier, Moral Prejudices; R.J. Lewicki and B.B. Bunker, "Developing and Maintaining Trust in Work Relationships," in Trust in Organization: Frontiers of Theory and Research, ed. R.M. Kramer and T.R. Tyler (London: Sage Publications, Inc., 1996).

29. See ref. 28, Lewicki and Bunker, "Developing and Maintaining Trust in Work Relationships."

30. L.K. Trevino, G.R. Weaver, D.G. Gibson and B.L. Toffler, "Managing Ethics and Legal Compliance: What Works and What Hurts," California Management Review 41, no. 2 (1999): 131-51.

31. See ref. 25, Brockner and Siegel, "Understanding the Interaction Between Procedural and Distributive Justice."

32. See ref. 25, Brockner and Siegel, "Understanding the Interaction Between Procedural and Distributive Justice." 